\title{
APROXIMACIÓN AL HUMOR DE TONO
}

Víctor Manuel Peláez Pérez Universidad de Alicante

Nos congratula el auge de los estudios en torno a los dramaturgos de la bautizada por José López Rubio «la otra generación del 27 », ya que revelan una realidad teatral relevante en la historia de los espectáculos dramáticos. No obstante, dicha proliferación de investigaciones no ha tratado por igual a sus cinco integrantes. El mayor número de trabajos se ha centrado en las figuras de Miguel Mihura y Jardiel Poncela. En la actualidad cobran fuerza los estudios sobre José López Rubio y Edgar Neville. La figura de Antonio de Lara, más conocido por su seudónimo Tono, ha acaparado escasos trabajos. No pretendemos reivindicar un prestigio como dramaturgo para este autor, cuyos espectáculos no alcanzan la categoría estética de sus compañeros de grupo. Sin embargo, no debemos pasar por alto la significación que tuvo para los autores de esta «hermandad del humor», según la llamó Julio Huélamo (López Rubio, 2003), así como cuál fue su propuesta en torno al humorismo. Sobre estas cuestiones versarán las siguientes líneas, que constituyen una propuesta de reconocimiento de este singular personaje del panorama cultural del segundo tercio del siglo $x x$ en España.

Tono trabajó en diferentes ámbitos culturales, de los cuales destacamos sus colaboraciones en la prensa escrita, tanto de caricaturista como de articulista, su trayectoria teatral y sus incursiones en el cine (Romera Castillo, 2001). A nosotros nos interesa su producción dramática, en la que ha influido notablemente su pasado como caricaturista; sobre todo, según 
expondremos más adelante, se deja ver esa influencia en el gusto por la parodia, tan próxima a la caricatura. Sus espectáculos no pasaron inadvertidos en su contexto y obtuvieron el reconocimiento de sus compañeros humoristas. A pesar de que las investigaciones actuales parcelen dicho grupo de dramaturgos del humor en tres secciones, integradas la primera por Jardiel Poncela, la segunda por Mihura y Tono y la tercera por Neville y López Rubio, la figura de Tono se erigió en el adalid del humor de todos ellos, según el testimonio temprano de Ramón Gómez de la Serna:

Poco a poco se fue formando un grupo alrededor [de Tono], que le jaleaba las salidas antes de que saliesen y ese grupo estaba formado por unos jóvenes de su edad que se llamaban Edgar Neville, López Rubio, Mihura, Jardiel y, más tarde, Álvaro de la Iglesia, Fuentes, Álvaro de Albornoz y Antonio Robles (López Rubio, 2003: 18).

Señala, además, el peregrino y fértil talento de Tono: «Me fui dando cuenta de que Tono era una manera de encarar el presente como si ya tuviese cara de porvenir y que ejercía una acción catalítica sobre los jóvenes que lo rodeaban» (López Rubio, 2003: 25). Y esa capacidad de atraer la atención de cuantos le rodean fue más allá de nuestras fronteras, puesto que fue él quien congenió más rápidamente con el humorista Charles Chaplin cuando acudió a Hollywood (López Rubio, 2003). Ese reconocimiento, no obstante, no supuso un elogio de su producción dramática, sino que era más bien la exaltación de una personalidad, según apreciamos de las palabras de José López Rubio: «Tono fue uno de los hombres con mayor inteligencia natural, con todas las intuiciones posibles que he conocido, sin haber pasado por las ciencias habituales. Su ingenio superaba su falta de preparación» (López Rubio, 2003: 51).

La personalidad excéntrica y el humor inverosímil de Tono fueron sus dos principales atributos, con los que consiguió llamar la atención de cuantos le rodeaban. Son numerosos los testimonios que describen la faceta singular de su personalidad. Recogemos uno de Jardiel Poncela, que hace hincapié en la improvisación del humorista y en su naturaleza inquieta:

[...] llega siempre preguntando por alguien. Cuando creemos que va afeitado, se ha dejado el bigote; cuando creemos que se ha dejado el bigote, se ha ido a París. Sus trajes grises - ¿es siempre el mismo o son varios iguales?- le hacen parecer un deportista de Dinamarca (Montero, 1993: 125).

De todos los humoristas de su generación, nadie como él supo integrar con tanto acierto la sorpresa en el marco de la cotidianidad. Todos 
los humoristas de esta «hermandad del humor» trabajaron la sorpresa en el ámbito de la ficción teatral. De hecho, César Oliva erige el gusto por la sorpresa en mecanismo escénico principal de estos humoristas (Oliva, 2001). Pero Tono consiguió hacer de la sorpresa un mecanismo ya no escénico, sino vital, con el que atrajo la atención de sus compañeros generacionales. Así lo manifestó José López Rubio: «las más impensadas sorpresas [...] El chiste convertido en humor y el humor convertido en absurdo, a dos pasos del surrealismo, que nos dejaba perplejos, cogidos de improviso») (López Rubio, 2003: 52).

Esa capacidad para las sorpresas, o salidas de las que nos hablaba Ramón Gómez de la Serna, le motivó a escribir greguerías, jaleado por sus conmilitones, en un acto de culto al Pontífice del Vaticano del Humor (López Rubio, 2003: 43). No obstante, apenas son los testimonios escritos que tenemos de esas prácticas humorísticas, puesto que en la mayoría de ocasiones sus greguerías no excedían el registro oral. Gracias a la publicación de su epistolario con José López Rubio hemos rescatado algunas de sus greguerías, que serían declamadas en las tertulias a las que solían acudir los miembros de este grupo del humor. No obstante, no alcanzaron ni la soltura ni el acierto estético de las de Gómez de la Serna. Citamos los siguientes ejemplos de greguería de Tono:

En todas las mesillas de noche de los hoteles hay un botón de calzoncillo.

El paisaje francés se diferencia del español en que hay un ciclista.

Todos los franceses llevan una cintita en el ojal. Parecen pares de calcetines sin estrenar.

En París se coge un bidet, se le va rodeando de cosas y se hace una casa.

Las francesas la chupan para no despeinarse.

Todas las señoras francesas que van con señoritas hablan francés, y claro, parecen señoras de compañía.

A los bigotes de París les nacen unos franceses muy pequeños.

En los espectáculos hay en la entrada un tribunal.

En los entreactos hay que pedirles permiso con dos dedos en alto, para ir a mear.

Los empleados del metro son las colillas de los billetes (López Rubio, 2003: 127).

Los testimonios recogidos son prueba suficiente de la significación que Tono tuvo entre los humoristas de su generación. Un cultivador de greguerías elogiado por el propio Ramón Gómez de la Serna, un innovador del humor reconocido por Jardiel Poncela y José López Rubio, un maestro del lenguaje requerido por Miguel Mihura para escribir Ni pobre 
ni rico sino todo lo contrario y para doblar en clave de humor la película Un bigote para dos. Una personalidad, en suma, que no pasó inadvertida en su contexto cultural y que hizo del humor un modo de vida, no sólo una opción estética.

Pero, ¿cuál es la concepción del humor que defendió Tono? ¿En qué consistían esas sorpresas o salidas que tanto le jaleaban sus amigos? ¿Qué fin pretendía con sus creaciones estéticas? Son interrogantes que nos conducen a revisar sus manifestaciones humorísticas desde el prisma de su intencionalidad original. Para ello, debemos conocer cuáles son sus antecedentes, qué sentido confiere al humor y el marco teatral en que se ubica. Así comprenderemos tanto su trayectoria vital como la estética, que constituyen una unidad más compacta que en los restantes miembros de su generación.

Diversos investigadores han señalado los principales pilares que han posibilitado la aparición de un nuevo concepto del humor, explotado por los integrantes de «la otra generación del 27». Cristóbal Cuevas (1993) señala cinco hitos artísticos ligados al humor del 27: en primer lugar, como antecedente más remoto, cita el humorismo desgarrador de Quevedo. Si la generación del 27 homenajeó a Góngora, su contrapunto humorístico acudiría a Quevedo; en segundo lugar, desde el terreno del arte pictórico, puede rastrearse el sentido de lo grotesco de Goya, como punto de partida para las deformaciones cómicas; en tercer lugar, hallaríamos el esperpentismo caricaturesco de Valle-Inclán; en cuarto lugar es evidente la huella del ingenio de Ramón Gómez de la Serna, como precedente inmediato y en contacto directo con los propios integrantes del grupo humorístico del 27; y en quinto lugar notamos el legado de lo guiñolesco, asociado a los conceptos de lo cómico y lo caricaturesco. Por su lado, Gómez Yebra (1995) incide en la influencia de tres dramaturgos concretos: por un lado, la comedia costumbrista de Jacinto Benavente; por otro lado, la tragedia grotesca de Carlos Arniches; y en último término, el astracán de Pedro Muñoz Seca.

No es éste el lugar de discutir la cuestión de los antecedentes estéticos del humor del 27. Sí queremos, no obstante, apuntar que la realidad es más compleja que cualquier relación de posibles influencias. La historia del humor, aunque en gran medida desconocida, está repleta de creaciones estéticas a lo largo de la historia literaria. Más que escoger algunos momentos, habría que enfatizar la relevancia que la literatura cómica y de humor ha tenido para el nacimiento de este grupo de humoristas. E1 humor siempre ha existido. Unas veces ha salido a la luz, gracias a algunas manifestaciones brillantes, pero otras veces ha pasado inadvertido, porque no ha aportado creaciones de gran valía estética. Es el caso de la 
segunda mitad del siglo XIX, tan rico en manifestaciones cómicas (teatro, narrativa, prensa...), pero tan desconocido para nosotros, debido al escaso valor estético, que no histórico, de la mayoría de esas creaciones. Hemos tenido que esperar al siglo xx para que, gracias a las creaciones cómicas de literatos de prestigio, reconozcamos una literatura de humor, que de inmediato hemos situado en los albores de este grupo humorístico del 27. Más adecuado sería situar el humor del 27 como resultado de toda esa corriente de literatura cómica que desde un siglo atrás venía gestándose en España. La renovación del 27 fue la reacción natural a un agotamiento de las fórmulas y técnicas del humor tradicional. Los dramaturgos que iniciaron esa renovación (Benavente, Arniches, Valle-Inclán, Muñoz Seca) fueron árboles solitarios en el ancho campo del humor. La revolución vino de mano de los miembros de la otra generación del 27 , que a grandes rasgos crearon un ideario común y escogieron a un líder, Ramón Gómez de la Serna.

A ello cabría unirle, al respecto de Tono, el hecho de que fuera una persona más intuitiva e ingeniosa que instruida, según apuntó el propio López Rubio, y que, por tanto, más que tener en mente unos modelos determinados de la tradición literaria, en realidad bebería de toda esa tradición humorística que copaba principalmente los escenarios y las páginas de revistas como Madrid Cómico, cuyo espíritu recogió posteriormente La Codorniz. Francisco Ruiz Ramón ligaba el humor de Tono al de Pedro Muñoz Seca, afirmando que su teatro «es, en cierto modo, la forma actual del nuevo astracán, con una comicidad tal vez más intelectual que la de su antecesor» (Ruiz Ramón, 1995: 335). Esa faceta intelectual nos permite pasar del umbral de lo cómico a lo humorístico en Tono, aunque sea una cuestión que entrañe algunas dificultades, en cuanto que el humor exclusivamente lingüístico que con carácter general cultiva Tono podría encasillarse en el campo de lo cómico; así lo señala, por ejemplo, José Monleón (2001). Sin embargo, el propio José López Rubio ubica a Tono en la esfera del humor intelectual, ya que lo contrasta con el esperpento valle-inclanesco y lo relaciona con el humor inverosímil de Ramón Gómez de la Serna, al afirmar sobre sus asuntos y personajes que, aunque estén tomados de la vida cotidiana o incluso de la ficción teatral, aparecen «desquiciados, fuera de su quicio normal, sometidos a un espejo deformador convexo (no cóncavo, como los de Valle), en un ramoniano estado de inverosimilitud» (López Rubio, 2003: 27).

Nosotros queremos hacer hincapié no ya en dramaturgos concretos, cuya filiación han demostrado plausiblemente los investigadores citados. Nuestro interés radica en el humor gráfico, que ilustraba las revistas desde el último tercio del siglo XIX (Tubau, 1973). Esa época finisecular fue el período dorado del género paródico, que se desarrolló prioritariamente en 
escenarios (Peláez, 2004) y en las páginas de periódicos y revistas (Beltrán, 1992). Tono incardinó sus primeros pasos en la tradición del humor gráfico, colaborando con caricaturas en periódicos y revistas. El arte de la caricatura es el de la deformación del modelo, es un arte que exige detallismo, precisión, agudeza visual e ingenio recreador (Rubio Jiménez, 2004). Esos rasgos son, por otra parte, los más idóneos para el cultivo de la parodia literaria, en cuya estela se inició Tono. Basta con citar algunos de sus títulos teatrales para darnos cuenta de la voluntad de recreación de modelos con que este humorista ingresó en el cuerpo de dramaturgos: Rebeco, Guillermo Hotel, Romeo y Julieta Martínez, Algo flota sobre Pepe, Las mil y una piernas, La viuda es sueño, Federica de Bramante y iQué bollo es vivir!, entre otros títulos, manifiestan con claridad la referencia literaria o fílmica de la que parten. José López Rubio incidió en esa faceta de dibujante de caricaturas como fuente primordial de la gracia menos formal y disparatada que caracterizó tanto la vida como la obra teatral de Tono. Caricatura, parodia, sorpresa, inverosimilitud, deformación y chiste son conceptos íntimamente ligados y que Tono supo trasladar desde su vocación de dibujante a sus creaciones teatrales.

Esa faceta de parodista nos permitirá comprender su concepción del humor, como punto esencial de este trabajo. Para ello tendremos que barajar las ideas de Tono en torno al humor y las ideas de otros humoristas de su grupo e investigadores, y corroborarlas en sus creaciones estéticas. Siendo Tono una persona escasamente instruida y más inclinada al ingenio que a teorizar, no resulta extraño que apenas encontremos unas líneas que presenten cuál es su idea del humor. No obstante, tampoco es una circunstancia exclusiva de este humorista, puesto que sabemos que Jardiel Poncela, por ejemplo, tampoco dejó apenas nada escrito sobre humor porque pensaba que dedicarse a esa tarea era una pérdida de tiempo (Escudero, 1981). Es más bien una actitud vital que una elección estética, porque sabemos que ninguno de estos autores dejó al azar la creación de sus obras. Máxime cuando a partir de 1939 la censura restringió las posibilidades de expansión estética del humorismo, amoldándose a un teatro de la evasión, de circunstancias y un teatro de lo inverosímil (Ruiz Ramón, 1993 y 1995; Monleón, 1993; Pascual, 1998).

Todas las ideas de Tono sobre el humor inciden en su carácter inofensivo, de juego de ruptura de moldes, sin más pretensiones que divertir desde el conocimiento de la tradición cultural. Es una concepción idéntica al juego que entraña el género paródico. El autor parte de un molde conocido por el lector y espectador $y$, a partir de ese conocimiento común, lo deforma, lo recrea, con objeto de presentar a ese lector-espectador una 
nueva versión que lo sorprenda y le haga consciente de los artificios y mecanismos convencionales del subtexto remedado. Tono lo expresa con la idea de la ruptura de moldes. Así lo encontramos en una de sus reffexiones dispersas en su Diario de un niño tonto. Situada la acción a finales de la década de los cuarenta, el niño Gustavo, trasunto de Tono, afirma en uno de los pasajes: «En una palabra: rompamos moldes de una vez, pues en la vida no hay nada tan bonito como romper moldes» (Lara, 1998: 44). Pero en esta ocasión deja sin aclarar la finalidad de romper moldes. Nosotros podemos conceder crédito a ese «no hay nada tan bonito como romper moldes» o pensar más bien que esa ruptura de moldes es su opción estética y vital para evadirse de la monotonía cotidiana e introducir el factor sorpresa, de raigambre surrealista, al que aludían Ramón Gómez de la Serna y José López Rubio. Y no era precisamente la opción del humor la más sencilla desde el prisma estético, ya que el mismo Jardiel Poncela había dicho que «lo cómico o lo humorístico es un rezume decantado de cultura, de inteligencia, de experiencia, de imaginación y de comprensión» (Escudero, 1981: 30).

Siempre que Tono hable del humor, hará hincapié en su carácter inofensivo, en la carencia de crítica. Enfatiza únicamente la naturaleza lúdica del humor. Algo por otro lado lógico en el contexto histórico en que nos desenvolvemos. Quizá unas de sus palabras más significativas sean las que escribe como paso previo a la escenificación de Guillermo Hotel. En ellas insiste en que no asoma crítica alguna en su espectáculo. Sólo trata de conseguir la risa del auditorio. Tengamos presente que las escribe pensando en el censor de espectáculos, que dará el visto bueno a su representación. Estas palabras las hallamos en un documento almacenado en el Archivo General de la Administración, cuyo contenido transcribimos a continuación:

Respetable público:

He aquí unas palabras del autor antes del estreno:

Cuando alguien escriba nuevamente el elogio de la risa, será forzoso que se detenga nuevamente en esa gran alameda del humor por el humor, de la alegría sin malicia y de la comicidad sin víctima. Hay muchos caminos para el humor cuando uno está decidido a disecar semejantes, atravesarles el alfiler de cabeza negra de la crítica, hacerles dar una vuelta en torno a sí y lanzarlos a la tentadora solicitud con que una gran mayoría de espectadores desea contemplar en ridículo a sus semejantes. No he llegado todavía a eso. Creo, por otra parte, que el teatro de hoy debe fomentar ese ansia de evasión que tortura y fatiga al mundo. Esta clave confiere al teatro de humor como a su hermano mayor, el teatro poético, un papel altísimo 
en la literatura moderna. Por eso escribo teatro y por eso he escrito Guillermo Hotel.

Dicho está que, por lo tanto, avanzo con Guillermo Hotel por el sendero de un humor sin ortigas, sin amargura y sin acidez. Tímidamente, mis personajes piden su venia para cruzar el arco del teatro, sin pretender, ni mucho menos, derribar sus columnas de papel pintado. Intactos quedan los viejos moldes, y más bien la preocupación de una carpintería sólida, precipita la comedia en compañía de las más clásicas. Un solo lugar de acción: habitación en el Guillermo Hotel. Un tiempo mínimo: veinticuatro horas escasas. Y dentro de este margen una teoría de personajes trastocados por un azar caprichoso y divertido.

Confío en que el buen tiempo de la primavera madrileña arranque muchas y buenas sonrisas a mi sencilla habitación de Guillermo Hotel'.

En estas palabras encontramos algunas ideas clave, que pueden resultar incluso contradictorias con la personalidad de Tono. Especialmente significativa es la afirmación «intactos quedan los viejos moldes». Recordemos que en su Diario de un niño tonto había dicho que «rompamos moldes de una vez, pues en la vida no hay nada tan bonito como romper moldes». Una persona que los ha roto desde sus inicios aboga por respetar los viejos moldes. Y lo hace, a nuestro juicio, para reafirmar el carácter ficticio de su espectáculo, para atribuirle cuanta más teatralidad sea posible en aras a la revisión del censor de representación. No significa que Tono no desee romper moldes. Únicamente supone un acto de dramaturgo en el purgatorio (Ruiz Ramón, 1993). En ese mismo sentido entendemos que afirme que no pretende «derribar sus columnas de papel pintado». Tono incide en la naturaleza teatral, ficticia, de su espectáculo, sin atisbo mínimo de realidad. Si no hay realidad, no hay peligro de censura. Y ante el peligro de que se asociaran las conductas ridículas de sus personajes con conductas de seres reales, el autor enfatiza el carácter inverosímil e irreal de su espectáculo.

Esa postura coincide con la naturaleza lúdica de que habíamos hablado anteriormente. Su propuesta es un juego teatral que divierta, sin necesidad de propiciar reflexiones ulteriores. Tono se ha incardinado, según sus palabras, en el «sendero de un humor sin ortigas, sin amargura y sin acidez», porque aún no se ha visto tentado a «disecar semejantes». Es la opción que le permitirá saltear la censura y estrenar sin apenas retoques

1.Documento depositado en el Archivo General de la Administración, en la sección de censura de teatros, Tono, Guillermo Hotel. Referencia del expediente 219-45, caja 71408. 
en sus textos. A lograr ese objetivo coadyuva el proceso de creación estética escogido, de filiación paródica. Si la realidad puede ser una fuente inadecuada para extraer argumentos humorísticos, la literatura y el cine aportan un inagotable número de motivos y argumentos que permitan su recreación cómica y que, a su vez, descarten cualquier posible vinculación con la realidad histórica del momento. Y si a ello añadimos que el género paródico carece de intencionalidad crítica, puesto que su único fin inherente es de naturaleza lúdica, obtenemos la fórmula idónea para la expresión estética de posguerra.

En esta opción Tono se ubica en los postulados de Valle-Inclán, cultivador de una parodia inteligente (Zamora Vicente, 1969), más allá de la astracanesca, pero sobre todo en la línea de su colega generacional Jardiel Poncela, en cuyos espectáculos asoman frecuentes pasajes paródicos. Pensemos en obras como Madre (el drama padre), parodia de los melodramas (Escudero, 1981), Margarita, Armando y su padre, remedo del amor romántico, centrado en La dama de las camelias, de Dumas (Ariza, 1974), o Angelina o el honor de un brigadier, recreación burlesca de los dramas del siglo xix (Ariza, 1974), con especial atención a la desmitificación de Don Juan (Gómez Yebra, 1993). Respecto de Tono ya apuntamos la relación de títulos teatrales paródicos, que nos conducen al ámbito dramático y al cinematográfico. Escoge situaciones de fácil reconocimiento para sus espectadores y, a partir de ellas, nos plantea un argumento sorprendente, apenas ligado a esa fuente original, o subtexto, de la que parte. Ejemplo de esta recreación de situaciones teatrales es la siguiente crónica del estreno de La viuda es sueño, escrita en colaboración con Jorge Llopis:

No es nueva la situación de la persona despierta, tras de un larguísimo sueño, en un mundo muy distinto del que conocía cuando se durmió. [...] El primer acto es muy prometedor, y está cargado de frases divertidísimas, aunque en el diálogo se adviertan sin dificultad elementos de distintas procedencias: la gracia moderna, hecha de puro y fresquísimo manejo verbal, que es característica de Tono, y un regreso a viejas fórmulas de chiste, que deberemos cargar a la cuenta del colaborador. El segundo acto, mal construido y con menos aciertos coloquiales, llega a aburrir, si se exceptúa una escena de amor a la moda de 1860, en la que Isabel Garcés, acompañada por Mariano Asquerino, desarrolló un trabajo admirable, de aguda comprensión y adecuación de un tipo delicioso. El tercer acto continúa la mala trayectoria, pero se salva por la escena final, poderosamente divertida, y en la que Isabel Garcés vuelve a ser insustituible (Fernández Cuenca, 1953: 8).

El cronista apunta que sólo la situación no es novedosa. Pero el desarrollo sí lo es. No hablemos, en consecuencia, de parodia teatral, porque la 
referencia del original no va más allá del título y de la situación que da pie al desarrollo dramático. Es evidente que no es la intención de Tono plantear una parodia del célebre espectáculo calderoniano. E igual sucede con la relación de títulos paródicos que apuntamos más arriba. En todos ellos la naturaleza paródica no supera los límites de la aquí reseñada. Únicamente establecemos una viable conexión con el género dada la naturaleza lúdica que preside tanto las creaciones paródicas como los espectáculos humorísticos de Tono. Este autor no escoge la parodia como opción estética, sino que se vale de ella a modo de subterfugio para atribuir un carácter marcadamente teatral a sus espectáculos. No quiere aparentemente que se relacionen sus espectáculos con el marco histórico, con la realidad en la que vive. Y para ello escoge situaciones del ámbito de la ficción teatral o cinematográfica (Cano Jiménez, 2001) y las recrea con originalidad, sin supuesta crítica.

Su opción de cultivar, como él mismo dijo, el terreno del «humor por el humor, de la alegría sin malicia y de la comicidad sin víctima» le sirvió para librarse de la censura y poder estrenar sin mayores inconvenientes (Muñoz Cáliz, 2001). Alguna tachadura, relacionada con expresiones del erotismo, tuvieron sus espectáculos Romeo y Julieta Martínez, Enredo de cacherulos, Bárbara, Don Pio descubre la primavera, Rebeco, iQué bollo es vivir!, Guillermo Hotel, Hoy como ayer y Los mejores años de nuestra tía. A modo de ejemplo, de Guillermo Hotel se tachó: «[no me abraces] que van a creer que no estamos casados» (Muñoz Cáliz, 2001: 150). Y de Bárbara se eliminaron acotaciones como «descubriendo las piernas dos dedos más arriba admite la censura» o «Carlos abraza a Bárbara y la besa. Esta vez de verdad», obligando a lo siguiente: «Se procurará en la escena de la exhibición de piernas y realización de besos no pasar de lo tolerado en la pantalla, exagerando el tono de parodia divertida, como es la intención del autor» (Muñoz Cáliz, 2001: 151). Vemos, en esta última cita, cómo incluso los censores aludían a la intencionalidad paródica de Tono, reafirmando la naturaleza teatral de sus espectáculos.

Pero, ¿será cierto ese humor por el humor? ¿No podremos vislumbrar un atisbo de malicia en sus producciones estéticas? El propio Tono afirmó en su previo a la representación de Guillermo Hotel que el teatro debe fomentar la «evasión» e incidió, como vimos, en ese «humor sin ortigas» que sólo sirva de divertimento. José López Rubio también negó la intencionalidad crítica tanto del grupo de humoristas como de Tono en particular. Del grupo dijo que «La España adusta era contemplada con la sonrisa amable de estos cinco autores que tuvieron por lema la alegría de vivir» (López Rubio, 2003: 38). Fue la actitud que predominó en La Codorniz, revista que, según López Rubio, «no destruirá nada sólido, quizá 
porque su misión sea destruir lo endeble, lo caduco, lo polvoriento, lo corrompido» (López Rubio, 2003: 36) ${ }^{2}$. Y de Tono afirmó encontrar en él «la bondad natural del ser con menos hiel que he conocido» (López Rubio, 2003: 53), un hombre «cuyo humor no tuvo aguijón ni malicia» (López Rubio, 2003: 56). Francisco Ruiz Ramón y José Monleón afirmaron de su teatro que no tuvo posibilidad de trascendencia, sólo cultivó el gracejo, a sabiendas de que cualquier intento de modificar la realidad sería inútil y peligroso (Ruiz Ramón, 1995; Monleón, 2001). Sin embargo, todo ello no quita la presencia esporádica de pasajes satíricos, irónicos y críticos en los escritos de Tono, que contradicen esa idea de la evasión y del humor sin amargura. Citaremos algunos ejemplos. En su Diario de un niño tonto, ubicada la acción a finales de la década de los cuarenta, encontramos afirmaciones como las siguientes:

- ¿De dónde saca usted los garbanzos?

-Me los trae la estraperlista -respondió la marquesa con un aire distinguidísimo. Después añadió: hoy los he pagado a 18 pesetas. Yo no sé adónde vamos a parar... (p. 14).

Así es que he pensado que como el maestro siga preguntándome tantas cosas, voy a dejar de ir al colegio y me voy a colocar en una oficina de información, que es donde nadie pregunta nada (p. 38).

-iTampoco te interesan los verbos?

-¿Los verbos?... ¿Qué quiere usted que haga con los verbos? Mi madre me dice que ahora lo único que tiene importancia es la comida, y no querrá usted que me coma los verbos (p. 60).

No comprendo cómo pueden esos señores [de la ONU], que entienden tanto de países, arreglar España estando en América, pues lo lógico sería que, si verdaderamente quieren arreglarla, vinieran aquí a plantar patatas, a criar vacas y a llover (p. 69).

2.Recordemos lo que dijo Miguel Mihura en torno a La Codorniz:

La Codorniz nació para tener una actitud sonriente ante la vida, para quitarle importancia a las cosas, para tomarle el pelo a la gente que veia la vida demasiado en serio, para acabar con los cascarrabias, para reírse del tópico y del lugar común, para inventar un mundo nuevo, irreal y fantástico y hacer que la gente olvidase el mundo incómodo y desagradable en que vivía (Monleón, 2001: 25). 
En su «drama de capa y bigote» Federica de Bramante o Las florecillas del fango, representado el 22 de diciembre de 1953, presenta fragmentos como los siguientes:

$\begin{array}{ll}\text { LILLO } & \text { ¡Ay, la vida está fatal! } \\ & \text { Vos no sabéis lo que es } \\ & \text { hacer la compra del mes } \\ & \text { tan sólo con un real. } \\ \text { ADELA } & \text { ¿Has reclamado en la tienda? } \\ & \text { En el arroz que has comprado, } \\ & \text { ¿qué diréis que me he encontrado? } \\ & \text { ¡Un empleado de Hacienda! } \\ \text { FEDERICA } \quad \begin{array}{l}\text { No extraño lo que recitas; } \\ \text { yo, en las lentejas de ayer, } \\ \text { cuando las iba a cocer, } \\ \text { encontré dos viejecitas. }\end{array} \\ \text { (Acto II) }\end{array}$

FEDERICA ¡Sí, veinte niños, Marqués!

¿Te parece acaso mucho?

MARQUÉS Es que si estos angelitos

responden a su abolengo, dentro de unos años tengo mil trescientos biznietos.

FEDERICA Reconozco tu alegato, pero si de esta me muero, con esos niños yo quiero que fundes un sindicato. ¡Todo fue pasar el rato, pero con tan mal cariz, que ya no sé a punto fijo si tengo o no tengo hijo, si soy feliz o infeliz, si soy corte o soy cortijo, si soy Velarde o Daoiz! i"Ser o no ser», como dijo Nicolás González Ruiz! (Acto III)

Como vemos en los ejemplos, en la España de posguerra Tono nos habla del estraperlo, de la administración, del hambre y de política. No responde precisamente al ideario de una literatura de evasión. Eso sí, sabe 
camuflar esos pasajes bajo una supuesta intencionalidad paródica, que le confiere inmunidad ante la censura. Ahora bien, la escasa presencia de episodios satíricos en la producción estética de Tono nos conduce a asentir, con Francisco Ruiz Ramón, que sería excesivo implicarle a sus obras un presunto sentido trascendental, ya social, ya político. Más bien cabría apuntarle el desarrollo de unos episodios que funcionan con valor de sátira de ciertas realidades del marco histórico, sin que ello suponga un desvío de la intencionalidad primaria del autor, que no es otra que divertir.

En ese propósito de mover a risa al lector y espectador, Tono hace uso de diversos mecanismos estéticos, que forman parte de su ideario del humor por el humor. Aunque hayamos visto que no se evade por completo de su realidad, el autor busca en otro terreno su fuente de la comicidad. Sobre todo, acude al terreno de los tópicos, que recoge para descoyuntarlos y presentarlos desde el prisma paródico. En concreto, el ámbito en que sobresalió Tono fue el del lenguaje. Ruiz Ramón ya habló de su ruptura sistemática de los clichés lingüísticos y de las frases hechas. No en vano, José López Rubio calificó a Tono de «pirotécnico verbal» (López Rubio, 2003: 23), en clara alusión a su facilidad para manejar el lenguaje, provocar la sorpresa y descubrir la vacuidad del lenguaje consagrado socialmente. Son constantes los dobles significados en sus chistes, que condensan la expresión, arrasan los tópicos y los someten a parodia. Y, sobre todo, busca la sorpresa, constante vital de Tono, según indicó José López Rubio: «su diálogo, una sucesión de juegos de lenguaje y de fuegos artificiales; unos golpes sucesivos desde todos los ángulos, capaces de desconcertar al espectador más avispado» (López Rubio, 2003: 55). Ésta es la cualidad reconocida de Tono, como apreciamos en la crónica del estreno de $L a$ viuda es sueño, arriba transcrita, en la que se le atribuía «la gracia moderna, hecha de puro y fresquísimo manejo verbal, que es característica de Tono». Su forma de evasión que desarrolló consistió en la parodia idiomática, unida al resto de recursos prototípicos de su generación (ruptura de la asociación lógica de ideas, intrigas disparatadas, quid pro quo...) (Oliva, 2001), en los que no destacó como los restantes compañeros de generación. De hecho, en las críticas de sus obras el único aspecto positivo que se reseña es su habilidad en el manejo del lenguaje. Así lo ponen de manifiesto quienes se han acercado a la producción estética de Tono.

He aquí la figura de Tono. Un humorista capaz de atraer la atención de cuantos le rodean gracias a su facilidad para el humor lingüístico. Una persona reconocida por sus compañeros de grupo y por el mismo Ramón Gómez de la Serna. Un literato que no se quedó en la evasión estética, pero tampoco buscó el compromiso. Un humorista que merece ser recordado por sus dotes de catalizador de una generación y por sus virtudes para la 
expresión cómica, aunque él mismo no deseara un protagonismo más allá de sus condiciones de humorista. Nos parecen adecuadas como resumen las palabras de José López Rubio respecto de Tono: «Aquel hombre [...] cuyo humor no tuvo aguijón ni malicia, no se tomó en serio a sí mismo, que es la primera regla del verdadero humor, hasta en los momentos en que el humor parece que ha de vacilar necesariamente, como un dulce pudor para ocultar las últimas flaquezas humanas» (López Rubio, 2003: 56). 


\section{BIBLIOGRAFÍA}

ArIZA, Manuel, Enrique Jardiel Poncela en la literatura humorística española, Madrid, Fragua, 1974.

Beltrán, Pablo, Salvador María Granés: autor del género chico y periodista satírico, Madrid, Universidad Complutense, 1992.

CANO JiMÉNEZ, Gema, «El cine en el teatro de Tono», en El teatro de humor en la guerra y la posguerra española (1936-1948), Marieta Cantos Casenave y Alberto Romero Ferrer (eds.), Cádiz, Publicaciones de la Universidad y Fundación Pedro Muñoz Seca, 2001, pp. 347-358.

Cuevas, Cristóbal (dir.), Jardiel Poncela. Teatro, vanguardia y humor, Barcelona, Anthropos, 1993.

Escudero, Carmen, Nueva aproximación a la dramaturgia de Jardiel Poncela, Cuadernos de la Cátedra de Teatro de la Universidad de Murcia, Murcia, 1981.

Fernández Cuenca, Carlos, «Un mes de teatro en Madrid», Teatro, 1953, enero, $n^{\circ} 3$, pp. 7-8.

Gómez Yebra, Antonio, «Desmitificación de Don Juan en Angelina o el honor de un brigadier», en Jardiel Poncela. Teatro, vanguardia y humor, Cristóbal Cuevas (dir.), Barcelona, Anthropos, 1993, pp. 171-194.

- Int. a Jardiel Poncela, Enrique, Usted tiene ojos de mujer fatal. Angelina o el honor de un brigadier, Madrid, Castalia, 1995.

LARA, Antonio de, y Jorge Llopis, Federica de Bramante o Las florecillas del fango, Madrid, Alfil, 1954.

- Diario de un niño tonto, Madrid, Temas de Hoy, 1998.

López Rubio, José, La otra generación del 27. Discurso y cartas, ed. José $\mathrm{M}^{\mathrm{a}}$ Torrijos, Madrid, CDT, 2003.

Mingote, Antonio, Tono: antología 1927-1977, Madrid, Prensa Española, 1978.

Monleón, José, «Jardiel Poncela o el teatro de ninguna parte», en Jardiel Poncela. Teatro, vanguardia y humor, Cristóbal Cuevas (dir.), Barcelona, Anthropos, 1993, pp. 65-78.

- «Teatro cómico y teatro de humor en la posguerra civil española», en El teatro de humor en la guerra y la posguerra española (19361948), Marieta Cantos Casenave y Alberto Romero Ferrer (eds.), Cádiz, Publicaciones de la Universidad y Fundación Pedro Muñoz Seca, 2001, pp. 15-35.

Montero, José, «Humor, pasión y drama en la vida de Enrique Jardiel Poncela», en Jardiel Poncela. Teatro, vanguardia y humor, Cristóbal Cuevas (dir.), Barcelona, Anthropos, 1993, pp. 119-138. 
Muñoz CÁlız, Berta, «La censura y el teatro de humor durante la primera década de la dictadura franquista (1939-1948)», en El teatro de humor en la guerra y la posguerra española (1936-1948), Marieta Cantos Casenave y Alberto Romero Ferrer (eds.), Cádiz, Publicaciones de la Universidad y Fundación Pedro Muñoz Seca, 2001, pp. 141-151.

Oliva, César, «Los mecanismos teatrales en la comedia de humor de la posguerra», en El teatro de humor en la guerra y la posguerra española (1936-1948), Marieta Cantos Casenave y Alberto Romero Ferrer (eds.), Cádiz, Publicaciones de la Universidad y Fundación Pedro Muñoz Seca, 2001, pp. 37-48.

PASCuAL, Itziar, «La generación del 27 del humor: modernidad y tradición», en Pedro Muñoz Seca y el teatro de humor contemporáneo (1898-1936), Marieta Cantos Casenave y Alberto Romero Ferrer (eds.), Cádiz, Publicaciones de la Universidad y Fundación Pedro Muñoz Seca, 1998, pp. 233-235.

Peláez Pérez, Víctor M., La parodia teatral en España, Alicante, Taller Digital (www.cervantesvirtual.com), 2004.

Romera Castillo, José, «Los dramaturgos del otro 27 (el del humor) reconstruyen su memoria», en El teatro de humor en la guerra y la posguerra española (1936-1948), Marieta Cantos Casenave y Alberto Romero Ferrer (eds.), Cádiz, Publicaciones de la Universidad y Fundación Pedro Muñoz Seca, 2001, pp. 49-66.

RuBıo JiMÉNEZ, Jesús, «El difícil arte de la caricatura escénica: astracán, tragedia grotesca y esperpento», en ¿De qué se venga Don Mendo? Teatro e intelectualidad en el primer tercio del siglo $X X$, Marieta Cantos Casenave y Alberto Romero Ferrer (dirs.), Cádiz, Fundación Pedro Muñoz Seca, 2004, pp. 201-223.

Ruiz Ramón, Francisco, «Jardiel Poncela: un dramaturgo en el purgatorio», en Jardiel Poncela. Teatro, vanguardia y humor, Cristóbal Cuevas (dir.), Barcelona, Anthropos, 1993, pp. 15-32.

Ruiz Ramon, Francisco, Historia del teatro español. Siglo xx, Madrid, Cátedra, 1995.

Tubau, Iván, De Tono a Perich: el chiste gráfico en la prensa española de la posguerra, Madrid, Fundación Juan March, 1973.

Zamora Vicente, Alonso, La realidad esperpéntica, Madrid, Gredos, 1969. 